\title{
Host and Viral Factors in Respiratory Syncytial Virus Infection
}

\author{
Peter Mastrangelo $\cdot$ Richard G. Hegele
}

Published online: 15 May 2013

(c) Springer Science + Business Media New York 2013

\begin{abstract}
Respiratory syncytial virus (RSV) is a major worldwide pathogen for which there is still no effective vaccine or antiviral treatment available, and immunoprophylaxis with RSV-specific antibodies (e.g., palivizumab) is used in limited clinical settings. In this review, we discuss virus-host interactions relevant to RSV pathobiology and how advances in cell and systems biology have accelerated knowledge in this area. We also highlight recent advances in understanding the relationship between RSV bronchiolitis and sequelae of recurrent wheezing and asthma, new findings into an intriguing interaction between RSV and air pollution, and exciting developments toward the goal of realizing a safe and effective RSV vaccine.
\end{abstract}

Keywords Respiratory syncytial virus · Viral pathogenesis - Virus-host interactions - Virus persistence Asthma $\cdot$ Allergy $\cdot$ Systems biology $\cdot$ Nucleolin ·

Air pollution · Vaccinology

\section{Introduction}

Respiratory syncytial virus (RSV) is a single-stranded, negative-polarity Pneumovirus that infects people of all ages worldwide [1•]. RSV is a frequent cause of upper respiratory tract infections and otitis media, and also causes

P. Mastrangelo $\cdot$ R. G. Hegele $(\bowtie)$

Department of Laboratory Medicine and Pathobiology,

University of Toronto, 6231-1 King's College Circle,

Toronto, ON M5S 1A8, Canada

e-mail: richard.hegele@utoronto.ca

R. G. Hegele

Department of Paediatric Laboratory Medicine, The Hospital for Sick Children, Toronto, ON, Canada serious lower respiratory tract infections such as bronchiolitis and pneumonia, particularly in infants and young children, immunocompromised individuals, and the elderly. RSV infections in early postnatal life have also been associated with the onset of allergic sensitization and recurrent wheezing/asthma. Despite almost 60 years having passed since the discovery of RSV, there is still no licensed vaccine available, and prophylaxis with immunoglobulin (palivizumab) is used only for a subset of "high-risk" children (e.g., preterm births, and infants with congenital heart disease, congenital immunodeficiency, and/or bronchopulmonary dysplasia). Although a number of pharmacological agents have been used in RSV therapy, their efficacy and effectiveness are poor [2].

Here, we will briefly review some viral and host factors implicated in the pathobiology of RSV infections, focusing on how the diversity of these factors might be related to the variability seen in clinical disease. Our discussion will also include comparing and contrasting characteristics of RSV infections in vitro versus in vivo; current perspectives on the relationship between RSV infections, pediatric allergy, and asthma; recent work that describes a novel relationship between RSV and particulate matter (air pollution); and prospects for the development and implementation of a safe, effective RSV vaccine.

\section{Viral and Host Factors in RSV Infection: Toward an Integrated Perspective}

RSV Structure

Human RSV is a filamentous enveloped virus in which the viral nucleic acid and structural and internal proteins are surrounded by a proteinaceous outer coat [3]. As an 
enveloped virus, RSV's general structure has similarities to that of influenza and parainfluenza viruses, metapneumoviruses, and coronaviruses, and contrasts with that of other common respiratory pathogens such as rhinoviruses and adenoviruses, which are nonenveloped. RSV has three envelope proteins: $\mathrm{G}$ (glycoprotein), F (fusion), and $\mathrm{SH}$ (small hydrophobic) [1•]. Heterogeneity in the G glycoprotein defines the two main subgroups of RSV, A and B [4]. Some literature suggests that RSV A strains produce more clinically severe infections than RSV B strains [5], but this contention has proven difficult to reproduce among different groups of investigators [6]. One strain of RSV A, so-called line 19 [7], appears to be of particular interest regarding mucus production and secretion of IL-13, a $T_{h} 2$ cytokine associated with allergic-type host responses (see below), and thereby contributing in part to the heterogeneity and severity of clinical manifestations. In addition, RSV G has a secreted form that binds host antibodies and thereby serves as an immunological "decoy" that facilitates continued viral replication [8]. RSV G is also considered to be a key attachment protein for the virus to bind to the cell surface to initiate infection; however, with the discovery and engineering of RSV strains deficient in G (so-called RSV $\Delta \mathrm{G}$ ) that are infectious, albeit at with much lower efficiency than virus expressing G, RSV G is neither sufficient nor necessary to cause infection [9].

By contrast, RSV F is crucial for fusion of the viral envelope to the host cell surface, since RSV $\Delta \mathrm{F}$ cannot enter cells on its own but rather requires a helper virus to initiate infection [10]. On free virus, RSV F exists in a "prefusion" form that undergoes an elegantly characterized conformational change during the fusion process $[11 \bullet, 12]$. In contrast to RSV G, RSV F is highly conserved between the two major subgroups of the virus [13]. RSV F and RSV G may have an overall "yin-yang" effect on host adaptive immune responses concerning $T_{h} 1-T_{h} 2$ balance. In brief, $T_{h} 1$ responses involve a subset of $\mathrm{CD} 4^{+}$lymphocytes producing cytokines such as interferon (IFN)- $\gamma$ and interleukin (IL)-2 considered important in delayed hypersensitivity and antiviral immunity, whereas $T_{h} 2$ responses involve production of inflammatory mediators such as IL-4, IL-5, and IL-13 by a different subset of $\mathrm{CD} 4{ }^{+}$lymphocytes and are implicated in allergy. RSV $F$ appears to stimulate $T_{h} 1$ cells, whereas RSV $G$ appears to stimulate $T_{h} 2$ responses, and clinical manifestations are believed to reflect whether the overall response is shifted toward $\mathrm{T}_{\mathrm{h}} 1$ or $\mathrm{T}_{\mathrm{h}} 2$, or remains in balance with regard to cytokine production [14].

The RSV SH protein, by analogy to similar proteins expressed in other viruses, may have a role in enhancing the permeability of the cell surface to molecules and ions [15]. The importance of this putative function of RSV SH is unclear, since genetically engineered strains of RSV in which SH is deleted appear to be essentially as efficient as wild-type virus in causing cellular infections [16]. There is increasing interest in SH as a potential viral antigen target in vaccine development (see later). Other RSV components, including nucleocapsid $(\mathrm{N})$, polymerase $(\mathrm{L})$, nonstructural components (NS1, NS2), phosphoprotein (P), and matrix (M, M2-1, M2-2) have been implicated in stimulating host antiviral responses (e.g., IFN- $\alpha$ and IFN- $\beta$ ) through effects in host cell signal transduction pathways and important nuclear transcription factors (e.g., NF- $\kappa \mathrm{B}$, AP-1). Further details of the role of nonenveloped proteins in RSV replication and host responses are provided in an excellent review by Collins and Melero [1 $\bullet$.

\section{RSV Infections In Vitro Versus In Vivo}

One of the biggest enigmas surrounding RSV pathobiology is the strong tropism the virus shows for infecting the human respiratory tract in vivo; in vitro, RSV establishes productive infection of virtually all mammalian cell types studied, including a wide variety of primary and continuous cells lines of epithelial cells [17], macrophages [18], other leukocytes [19], fibroblasts [20], and even neurons [21]. In fact, finding a cell type that is resistant to RSV infection in vitro is challenging. As will be discussed in "Nucleolin as a Fusion Receptor for RSV: From Discovery to Drug Targeting" in the context of the discovery of a cellular fusion receptor for RSV, Sf9 cells from the moth Spodoptera frugiperda are difficult to infect with RSV [22]. In a definitive autopsy study of the lung pathology of untreated acute RSV infections, Johnson et al. [23] reported that RSV antigens were observed within airway and alveolar epithelial cells, as well as pulmonary macrophages. Similar observations have been made in experimental animals. In a guinea pig model of experimental RSV infection, our group has documented the expression of viral antigens via immunohistochemistry within lung epithelial cells, alveolar macrophages, interstitial cells (presumably dendritic cells), and cells within bronchusassociated lymphoid tissue, for at least 100 days after RSV inoculation [24]. A recent study has reported that RSV can be detected in approximately $15 \%$ of human tonsils of children with chronic adenotonsillar disease [25•]. Given the abundant literature concerning the effects of RSV infection on the secretion of various inflammatory mediators, responses of cell signaling pathways, and other host responses observed in vitro, one must exercise caution in extrapolating the significance of observations made in vitro to the in vivo state, and whether they represent opportunities for potential clinical interventions. One only needs to reflect on the historically disappointing results seen with attempts to treat RSV infections of experimental animals or patients with antiviral or anti-inflammatory agents to appreciate this point $[2,26]$. 
In contrast to other viruses such as influenza virus and adenovirus, where extensive cytotoxicity and cell death is the norm with infection in vitro, RSV infection does not elicit much in the way of cell damage [17]. There is evidence that RSV can actually decrease the rate of apoptosis in vitro [27]. Taken further, RSV has clearly been shown to cause persistent, noncytolytic infection of epithelial cells in vitro [28]. RSV persistence, characterized by continuous, low-level replication of infectious virus, has been described in vivo, first in a model in which cotton rats were immunosuppressed with cyclophosphamide [29], and subsequently in immunocompetent guinea pigs [30] and in mice [31, 32]. There is also evidence consistent with RSV persistence in humans, best characterized in the setting of adult patients with chronic obstructive pulmonary disease [33]. A possible role for RSV persistence in the pathobiology of postbronchiolitis wheezing/asthma is described in "RSV and Pediatric Asthma: Have We Found the Missing Link?"

\section{RSV-Host Interactions: Moving Ever More Proximally}

For many years, investigation of RSV-host interactions focused on characterizing the inflammatory mediator responses of infected cells, animals, and human subjects with the hope that an understanding of the virus-specific host responses to RSV infections could inform possible interventions designed to modulate relevant inflammatory mediators and thereby lead to improved clinical outcomes [34]. The apparent heterogeneity in virus-specific immunity observed in host adaptive immune responses to RSV (both cell-mediated and humoral), depending on the population studied, complicates the ability to make clinically relevant advances. Extensive inquiries have focused on innate immune mechanisms in the early host response to $\operatorname{RSV}[35,36]$. One rationale for this approach is that by understanding the early, "proximal" events that occur in RSV infections, it may be easier to develop effective clinical interventions that could be used effectively among diverse hosts who have different adaptive immune responses to the virus $[15,37]$. This rationale has been recently questioned, since apparent differences in innate immune responses have been observed between RSV A and RSV B infections [38].

Nevertheless, research into the role of innate immune mechanisms in RSV pathobiology led to a number of profound insights, one of which was the ability of RSV to increase the level of pattern-recognition receptors (e.g., Toll-like receptors) expressed on the cell surface [39]. These observations were influential to the field for a number of reasons: for example, the nature of cell surface molecules involved in innate immunity that can be affected by RSV was poorly understood, and pattern-recognition receptors (e.g., Toll-like receptor 4 and others) stimulate cell signaling pathways that are amenable to pharmacological manipulation [40], even if they are not actual receptors for the virus [41]. One cell signaling molecule related to Tolllike receptor interaction with RSV is p38 mitogen-activated protein kinase, as revealed by a screen of cultured cells with a panel of pharmacological kinase inhibitors. Inhibition of p38 mitogen-activated protein kinase with SB203580 (a compound originally developed for treatment of arthritis and cancer) was associated with marked inhibition of RSV replication in cultured cells, without inducing significant drug-related cytotoxicity [42]. This type of experiment is an example of so-called drug repurposing, in which a compound developed for an unrelated clinical indication can be given on the basis of pathobiology defined in another clinical setting [43]. It remains to be seen whether such an approach to drug repurposing will be useful in the management of RSV infections in vivo in animal models, and ultimately in humans.

Nucleolin as a Fusion Receptor for RSV: From Discovery to Drug Targeting

Our group identified cell surface nucleolin as a molecule that fulfills the criteria of a functional receptor for RSV [44•]. One of the key challenges to overcome in this discovery was finding a cell type resistant to RSV infection in vitro which could become permissive after forced expression of the human nucleolin gene and ectopic expression of human nucleolin protein on the cell surface. This was achieved by use of insect Sf9 cells [22]. Validation of nucleolin as a cellular receptor in vivo was accomplished in a mouse model by small interfering RNA knockdown of nucleolin prior to RSV challenge, which was associated with a significant decrease in RSV titers as measured by quantitative plaque assays of lung homogenates. We showed that RSV F, not RSV G, interacts with nucleolin, and we coined the term "fusion receptor" to denote this fact.

Nucleolin is an especially challenging potential drug target for RSV. Nucleolin has a very short half-life when expressed on the cell surface, and constantly undergoes recycling between the cytoplasmic and nuclear compartments of the cell [45]. Thus, approaches that interfere with cell surface nucleolin such as use of nucleolin-specific blocking antibodies, result in the antibody-nucleolin complex being internalized into the cell and new ("fresh") unbound nucleolin moving to the surface [46]. This phenomenon could explain why in our antibody neutralization experiments attempting to validate nucleolin as an RSV receptor we were able to achieve only on the order approximately 70-80\% decreased infection of cells that had been preincubated with nucleolin-specific antibody 
prior to RSV challenge. Secondly, nucleolin is a notoriously "sticky" molecule that can bind all sorts of molecules, including proteins expressed by other viruses (e.g., parainfluenza virus type 3 , HIV), certain drugs (e.g., midkine, lactoferrin, pseudopeptide HB-19), and even DNA moieties (reviewed in [47]). How to translate this situation into a scenario that is RSV-specific needs to be addressed. Moreover, nucleolin does not exist in isolation on the cell surface; rather, it is part of a multiprotein complex of molecular mass of approximately $500 \mathrm{kDa}$ [48]. To add further context, intranuclear nucleolin is essential to cell survival and replication: inhibiting nucleolin in an undesired cellular compartment could elicit serious off-target effects [49]. Overall, the identification of nucleolin as a fusion receptor for RSV poses a number of profound challenges to be overcome before it may serve as a bona fide drug target.

\section{A Renaissance of RSV Cell Biology, and the Growing Role of Systems Biology}

One area of increasing research activity is the intracellular compartmentalization of RSV constituents during the viral life cycle. Cell biologists investigating RSV replication kinetics demonstrated that the virus does not necessarily follow a stereotyped replicative cycle, but rather can be preferentially directed into intracellular compartments that favor or inhibit replication [50, 51]. For example, cytoplasmic stress granules [52], caveolae [53], host cytoskeleton [54], and lipid rafts [55] have been reported to interact with RSV, and these are potential novel targets for pharmacological intervention. Increasingly, the use of highthroughput "systems biology" approaches designed to interrogate RSV-infected cells in an unbiased manner has led to identification of novel candidate molecules that could potentially be targeted pharmacologically [56, 57]. Systems biology permits the application of informatics related to pathway modeling relevant to RSV infection. By defining so-called interactomes [58 $]$ in which the virus affects cell function, investigators aim to achieve a comprehensive understanding of RSV-host interactions to inform the development of novel strategies in treatment and prophylaxis. One of the current limitations of informatics approaches is that the biological pathways being modeling are themselves incompletely characterized, so meaningful interpretations will require ongoing iterative activity [59].

\section{RSV and Pediatric Asthma: Have We Found the Missing Link?}

Within a few years of the discovery of RSV, in a seminal article, Wittig et al. [60] reported that a sizeable percentage
(32\%) of infants and young children hospitalized for RSV bronchiolitis developed sequelae of recurrent wheezing and asthma symptoms. These findings have been replicated on a number of occasions over the last few decades, although there is some ongoing controversy over whether patients can "outgrow" their asthma by the time they reach adolescence, or whether their condition can persist into adulthood [61-63]. One possibility is that RSV bronchiolitis is a "marker" of children who are genetically predisposed to develop asthma, as evidenced by a classic study in which RSV-specific IgE was documented in children who had recurrent wheezing as a sequela of RSV infection [64]. Further, in a highly influential article, Frick et al. [65] reported a temporal relationship between viral infection (particularly RSV and parainfluenza virus) and triggering allergic sensitization in 14 children born into "high-risk" families (i.e., where first-degree relatives had a proven history of allergy). This latter association has also been confirmed in larger studies, including the Canadian Asthma Primary Prevention Study of approximately 400 "highrisk" children and their families [66].

To explore potential mechanisms of postbronchiolitis wheezing/asthma and allergy, our group developed a guinea pig model of experimental RSV lung infection [67]. Guinea pigs were chosen because they were already a model of human parainfluenza virus type 3 infection [68], and could readily be sensitized to allergen (aerosolized ovalbumin) [69]. After initial work establishing that RSV protein and genome could persist in the guinea pig lung for up least 60 days after RSV inoculation [70], subsequent studies showed that outbred Cam Hartley guinea pigs could harbor replicating virus for at least 60-100 days after inoculation, in association with nonspecific airway hyperresponsiveness (AHR) and chronic airway inflammation (physiological and pathological hallmarks of asthma) $[24,30]$. However, in subsequent work, we noted that viral persistence on its own is not sufficient to produce asthmalike changes in the lungs, as inbred, "allergy-resistant" strain 2 guinea pigs can also develop persistent RSV lung infections but these animals do not get AHR or chronic airway inflammation in association with virus persistence [71].

Concerning the possibility that RSV infection is a "marker" of genetic predisposition to allergy, we observed that RSV infection of Cam Hartley guinea pigs enhanced allergic sensitization to aerosolized ovalbumin, consistent with this hypothesis [72]. Interestingly, the extent of chronic AHR/airway inflammation and virus-enhanced ovalbumin sensitization could be ameliorated by immunoprophylaxis of animals with CpG-oligodinucleotides (CpG-ODN), a potent $\mathrm{T}_{\mathrm{h}} 1$ stimulus [73]. Taken together, these results suggest that the combination of RSV and aeroallergen produces additive effects on AHR and airway 
inflammation in an "allergy-susceptible" host and that CpG-ODN immunoprophylaxis appears to target the RSVassociated, not the allergen-associated, component.

A large number of human studies have characterized differences in the types of cytokines and other chemical mediators of inflammation-and their potential genetic determinants-in different subsets of RSV-infected patients (reviewed in Zeng et al. [74•]). This large body of work provides valuable insights into possible differences in host responses to RSV infection and may be relevant to explaining why some infected individuals develop mild, upper respiratory tract infections whereas other individuals develop bronchiolitis or pneumonia, or go on to develop recurrent wheezing/asthma. Unfortunately, there has been a recurrent difficulty in validating the large number of candidate molecules/genes by replication in other cohorts, and the overall picture is far from clear [1•]. The use of a systems biology approach (see "A Renaissance of RSV Cell Biology, and the Growing Role of Systems Biology") promises to accelerate knowledge of identification of candidate molecules and genes for validation. One recent study [75.] has reported an exciting development that may provide a clue to the possible biological "missing link" between severe RSV infections and the subsequent development of pediatric asthma. In a series of experiments that began with unbiased interrogation of cells to identify candidate genes, followed by validation in experimental animals and analysis of human cohorts, investigators have characterized genetic polymorphisms in the promoter region to NFKBIA as having both functional and clinical significance in the context of RSV bronchiolitis and pediatric asthma. NFKBIA is the gene which encodes $\operatorname{I} \kappa \mathrm{B} \alpha$, the major negative regulator of NF- $\kappa B$. NF- $\kappa B$ is an important nuclear transcription factor that has a central role in regulating multiple host immune and inflammatory response elements. NFKBIA may end up as the unifying concept for bronchiolitis and allergy, as implicated by the results of this study, and this opens up exciting new research directions for patient identification, stratification, and targeted therapy.

\section{RSV and Particulate Matter: An Even Tighter Bond Than Previously Thought?}

Every day, humans are bombarded with numerous inhaled agents from the indoor and outdoor environment. Particulate matter related to air pollution is but one example of such an agent. Previous work that studied interactions between RSV and particulate matter focused on effects on the cellular inflammatory response in vitro [76-79] and on a larger scale on defining temporal relationships between air pollution exposure and virus infections and their effects on respiratory health $[80,81]$. From these studies, it is apparent that air pollution should be considered as a potential confounder of the effectiveness of RSV interventions.

A recent study has provided an even more dramatic relationship between RSV and particulate matter [82•]. In this work, "designer particles" of specific chemical composition were conjugated to human RSV, and cell cultures were inoculated with these complexes, with statistically significant responses observed with respect to cytokine production by cells. Interestingly, the same study showed that RSV conjugated to these particles could remain infectious at ambient room temperature for at least 2 months after preparation, without the need for cell culture, or freezing stocks to low temperature $\left(-80^{\circ} \mathrm{C}\right.$ or below). These observations open up an entirely new potential mechanism for RSV survival outside living organisms, and suggest a mode of environmental transmission of RSV, separate from close contact of individuals to virus-containing droplets or fomites. Obtaining improved understanding of the implications of RSV conjugated to particulate matter requires further research.

\section{Progress Toward an RSV Vaccine: Closer than Ever}

Since the discovery of RSV in 1955-1957 [83-85], vaccine development has been a major priority, yet there are a number of logistical considerations related to RSV infections affecting progress in this area, as Crowe [86] summarized over a decade ago (Table 1).

The tragedy that occurred in the 1960s with a candidate RSV vaccine that was prepared by formalin inactivation of whole virus that underwent field trials is well documented [87]. Briefly, vaccine recipients paradoxically developed severer clinical disease on RSV exposure, and there were several deaths in the vaccinated group. The mechanisms responsible for vaccine-enhanced illness were ultimately determined decades later by use of animal models. Through application of the $\mathrm{T}_{\mathrm{h}} 1-\mathrm{T}_{\mathrm{h}} 2$ paradigm of $\mathrm{CD}^{+}$lymphocytes, investigators determined that exposure of experimental animals to formalin-inactivated RSV vaccine resulted in an exaggerated host $T_{h} 2$ response after subsequent exposure to infectious virus. This has stimulated considerable research activity with the aim to design vaccines that shift the $T_{h} 1-T_{h} 2$ balance toward $T_{h} 1[88,89]$. However, this may be an overly simplistic approach, as a recent study in mice has reported that shifting the host immune response toward $T_{h} 1$ actually decreases the production of RSV-neutralizing antibodies, which would have the effect of limiting the effectiveness of a vaccine [90•]. In addition to $T_{h} 1$ and $T_{h} 2$ lymphocytes, the subpopulation of $\mathrm{T}_{\mathrm{h}} 17$ lymphocytes has been implicated in RSV infection, further adding to the complexity of the host immune response [91]. 
Table 1 Obstacles to RSV vaccine development

Animal models are not fully permissive for infection

Requirement for bivalent vaccine (two antigenic subgroups)

Young age of primary vaccine target population

Special safety concern when immunizing neonates

Immunologic immaturity of neonatal target population

Maternal antibodies inhibit immune responses in the target population

Disease occurs at the portal of entry (the respiratory mucosa)

Mucosal immunity to respiratory viruses is short-lived and incomplete

FI-RSV vaccine caused enhanced disease

Reproduced with permission from Crowe [86]

In recent years, a number of innovative and clever approaches for vaccine engineering have been developed, including the production of virus-like particles [92], chimeric live virus vectors [93], gene-based vectors [94], and the use of novel adjuvants [95]. At present, we are aware of a variety of candidate RSV vaccines (on the order of ten to 20 different products at various stages of development) poised to enter human clinical trials, which will be updated at the RSV Vaccine Conference (Porto, Portugal, October 2013: http://www.meetingsmanagement.com/rsvvw_2013). It is difficult to predict which, if any, of these products could end up as an effective vaccine for widespread use in humans. Currently, the goal is for there to be a simultaneous concerted effort in continued scientific vaccinology and in the careful design of human clinical trial protocols, including the possibility of immunizing pregnant women as a form of prenatal vaccination, in an effort to definitively solve the long-standing problem of determining and implementing a safe, effective RSV vaccine. Achieving this outcome would represent a glorious accomplishment for humankind and have enormous and lasting impact around the globe.

\section{Conclusions}

We are living in an era of accelerated activity and progress in our understanding of viral and host factors in RSV infection, and are poised to translate discoveries made in this realm into the clinic to achieve improved health outcomes for acute RSV infections and their sequelae. Research has evolved from characterizing RSV-host interactions to the identification of new targets for vaccine and pharmaceutical development. Advances in systems biology, informatics, cell and structural biology, and biological engineering have provided new and powerful approaches to study RSV infections, and the influence of other environmental factors such as allergens and particulate matter. We are closer than ever to achieving the dream of a safe, effective RSV vaccine, and the future promises to be exciting and rewarding.

Disclosure Peter Mastrangelo and Richard G. Hegele declare that they have no conflicts of interest.

\section{References}

Papers of particular interest, published recently, have been highlighted as:

- Of importance

1. Collins PL, Melero JA. Progress in understanding and controlling respiratory syncytial virus: still crazy after all these years. Virus Res. 2011;162:80-99. This is a recent comprehensive review of $R S V$.

2. Welliver RC. Pharmacotherapy of respiratory syncytial virus infection. Curr Opin Pharmacol. 2010;10:289-93.

3. Shaikh FY, Utley TJ, Craven RE, et al. Respiratory syncytial virus assembles into structured filamentous virion particles independently of host cytoskeleton and related proteins. PLoS ONE. 2012;7:e40826.

4. Mufson MA, Orvell C, Rafnar B, Norrby E. Two distinct types of human respiratory syncytial virus. J Gen Virol. 1985;66:2111-24.

5. McConnachie KM, Hall CB, Walsh EE, Roghmann KJ. Variation in severity of respiratory syncytial virus infections with subtype. J Pediatr. 1990;117:52-62.

6. Brandenburg AH, van Beek R, Moll HA, Osterhaus AD, Claas EC. $G$ protein variation in respiratory syncytial virus group $A$ does not correlate with clinical severity. J Clin Microbiol. 2000; 38:3849-52.

7. Moore ML, Chi MS, Luongo C, et al. A chimeric A2 strain of respiratory syncytial virus (RSV) with the fusion protein of RSV strain line 19 exhibits enhanced viral load, mucus, and airway dysfunction. J Virol. 2009;83:4185-94.

8. Bukreyev A, Yang L, Fricke J, et al. The secreted form of respiratory syncytial virus $G$ glycoprotein helps the virus evade antibody-mediated restriction of replication by acting as an antigen decoy and through effects on Fc receptor-bearing leukocytes. J Virol. 2008;82:12191-204.

9. Techaarpornkul S, Collins PL, Peeples ME. Respiratory syncytial virus with the fusion protein as its only viral glycoprotein is less dependent on cellular glycosaminoglycans for attachment than complete virus. Virology. 2002;294:296-304.

10. Batonick M, Oomens AGP, Wertz GW. Human respiratory syncytial virus glycoproteins are not required for apical targeting and release from polarized epithelial cells. J Virol. 2008;82:8664-72.

11. McLellan JS, Chen M, Kim A, et al. Structural basis of respiratory syncytial virus neutralization with motavizumab. Nat Struct Mol Biol. 2010;17:248-250. This is an outstanding example of advances in structural biology proving information on the interaction of RSV with antibodies.

12. McLellan JS, Yang Y, Graham BS, Kwong PD. Structure of the respiratory syncytial virus fusion glycoprotein in the post-fusion conformation reveals preservation of neutralizing epitopes. J Virol. 2011;85:7788-96.

13. Johnson PR, Collins PL. The fusion glycoproteins of human respiratory syncytial virus of subgroups $\mathrm{A}$ and $\mathrm{B}$ : sequence conservation provides a structural basis for antigenic relatedness. J Gen Virol. 1988;69:2623-8. 
14. Alwan W, Openshaw P. Distinct patterns of T- and B-cell immunity to respiratory syncytial virus induced by individual viral proteins. Vaccine. 1993;11:431-7.

15. Triantafilou K, Kar S, Vakakis E, Kotecha S, Triantafilou M. Human respiratory syncytial virus viroporin $\mathrm{SH}$ : a viral recognition pathway used by the host to signal inflammasome activation. Thorax. 2013;68:66-75.

16. Techaarpornkul S, Barretto N, Peeples ME. Functional analysis of recombinant respiratory syncytial virus deletion mutants lacking the small hydrophobic and/or attachment glycoprotein gene. J Virol. 2001;75:6825-34.

17. Zhang L, Peeples ME, Boucher GC, et al. Respiratory syncytial virus infection of human airway epithelial cells is polarized, specific to ciliated cells, and without obvious cytopathology. J Virol. 2002;76:5654-66.

18. Panuska JR, Cirino NM, Midulla F, Despot JE, McFadden ER Jr, Huang TY. Productive infection of isolated human alveolar macrophages by respiratory syncytial virus. J Clin Invest. 1990; $86: 113-9$.

19. de Graaff PM, de Jong EC, van Capel TM, et al. Respiratory syncytial virus infection of monocyte-derived dendritic cells decreases their capacity to activate CD4 T cells. J Immunol. 2005;175:5904-11.

20. Arens MQ, Swierkosz EM, Schmidt RR, Armstrong T, Rivetna KA. Enhanced isolation of respiratory syncytial virus in cell culture. J Clin Microbiol. 1986;23:800-2.

21. Li XQ, Fu ZF, Alvarez R, Henderson C, Tripp RA. Respiratory syncytial virus (RSV) infects neuronal cells and processes that innervate the lung by a process involving RSV G protein. J Virol. 2006;80:537-40.

22. Osiowy C, Anderson R. Neutralization of respiratory syncytial virus after cell attachment. J Virol. 1995;69:1271-4.

23. Johnson JE, Gonzales RA, Olson SJ, Wright PF, Graham BS. The histopathology of fatal untreated human respiratory syncytial virus infection. Mod Pathol. 2007;20:108-19.

24. Bramley AM, Vitalis TZ, Wiggs BR, Hegele RG. Effects of respiratory syncytial virus persistence on airway responsiveness and inflammation in guinea-pigs. Eur Respir J. 1999;14:1061-7.

25. - Proenca-Modena JL, Pereira Valera FC, Jacob MG, et al. High rates of detection of respiratory viruses in tonsillar tissues from children with chronic adenotonsillar disease. PLoS One. 2012; 7:e42136. This provides new evidence of expanded RSV tissue tropism.

26. Rosenberg HF, Domachowske JB. Inflammatory responses to respiratory syncytial virus (RSV) infection and the development of immunomodulatory pharmacotherapeutics. Curr Med Chem. 2012;19:1424-31.

27. Groskreutz DJ, Monick MM, Yarovinsky TO, et al. Respiratory syncytial virus decreases 553 protein to prolong survival of airway epithelial cells. J Immunol. 2007;179:2741-7.

28. Pringle CR, Shirodaria PV, Cash P, Chiswell DJ, Malloy P. Initiation and maintenance of persistent infection by respiratory syncytial virus. J Virol. 1978;28:199-211.

29. Wong DT, Rosenband M, Hovey K, Ogra PL. Respiratory syncytial virus infection in immunosuppressed animals: implications in human infection. J Med Virol. 1985;17:359-70.

30. Dakhama A, Vitalis TZ, Hegele RG. Persistence of respiratory syncytial virus (RSV) infection and development of RSV-specific IgG1 response in a guinea-pig model of acute bronchiolitis. Eur Respir J. 1997;10:20-6.

31. Schwarze J, O'Donnell DR, Rohwedder A, Openshaw PJ. Latency and persistence of respiratory syncytial virus despite $\mathrm{T}$ cell immunity. Am J Respir Crit Care Med. 2004;169:801-5.

32. Mejías A, Chávez-Bueno S, Gómez AM, et al. Respiratory syncytial virus persistence: evidence in the mouse model. Pediatr Infect Dis J. 2008;27(10 Suppl):S60-2.
33. Falsey AR, Formica MA, Hennessey PA, Criddle MM, Sullender WM, Walsh EE. Detection of respiratory syncytial virus in adults with chronic obstructive pulmonary disease. Am J Respir Crit Care Med. 2006;173:639-43.

34. Habibi MS, Openshaw PJ. Benefit and harm from immunity to respiratory syncytial virus: implications for treatment. Curr Opin Infect Dis. 2012;25:687-94.

35. Wang H, Peters N, Schwarze J. Plasmacytoid dendritic cells limit viral replication, pulmonary inflammation, and airway hyperresponsiveness in respiratory syncytial virus infection. J Immunol. 2006; 177:6263-70.

36. Mella C, Suarez-Arrabal MC, Lopez S, et al. Innate immune dysfunction is associated with enhanced disease severity in infants with severe respiratory syncytial virus bronchiolitis. J Infect Dis. 2013;207:564-73.

37. Garg R, Shrivastava P, van Drunen Littel-van den Hurk S. The role of dendritic cells in innate and adaptive immunity to respiratory syncytial virus, and implications for vaccine development. Expert Rev Vaccines. 2012;11:1441-57.

38. Wu W, Macdonald A, Hiscox JA, Barr JN. Different NF- $\kappa B$ activation characteristics of human respiratory syncytial virus subgroups A and B. Microb Pathog. 2012;52:184-91.

39. Puthothu B, Forster J, Heinzmann A, Krueger M. TLR-4 and CD14 polymorphisms in respiratory syncytial virus associated disease. Dis Markers. 2006;22:303-8.

40. Seki E, Yoshizumi M, Tanaka R, et al. Cytokine profiles, signalling pathways and effects of fluticasone propionate in respiratory syncytial virus-infected human foetal lung fibroblasts. Cell Biol Int. 2013. doi:10.1002/cbin.10044.

41. Marr N, Turvey SE. Role of human TLR4 in respiratory syncytial virus-induced $\mathrm{NF}-\kappa \mathrm{B}$ activation, viral entry and replication. Innate Immun. 2012;18:856-65.

42. Marchant D, Singhera GK, Utokaparch S, et al. Toll-like receptor 4-mediated activation of $\mathrm{p} 38$ mitogen-activated protein kinase is a determinant of respiratory virus entry and tropism. J Virol. 2010;84:11359-73.

43. Cavalla D. Predictive methods in drug repurposing: gold mine or just a bigger haystack? Drug Discov Today. 2012. doi:10.1016/ j.drudis.2012.12.009.

44. - Tayyari F, Marchant D, Moraes TJ, Duan W, Mastrangelo P, Hegele RG. Identification of nucleolin as a cellular receptor for human respiratory syncytial virus. Nat Med. 2011;17:1132-1135. This describes the discovery and characterization of the RSV fusion receptor.

45. Hovanessian AG, Soundaramourty C, El Khoury D, Nondier I, Svab J, Krust B. Surface expressed nucleolin is constantly induced to mediate calcium-dependent ligand internalization. PLoS ONE. 2010;5:e15787.

46. Deng JS, Ballou B, Hofmeister JK. Internalization of anti-nucleolin antibody into viable HEp-2 cells. Mol Biol Rep. 1996;23: 191-5.

47. Chen X, Kube DM, Cooper DJ, Davis PB. Cell surface nucleolin serves as a receptor for DNA nanoparticles composed of pegylated polylysine and DNA. Mol Ther. 2007;16:333-42.

48. Krust B, El Khoury D, Nondier I, Soundaramourty C, Hovanessian AG. Targeting surface nucleolin with multivalent MH-19 and related Nucant pseudopeptides results in distinct inhibitory mechanisms depending on the malignant tumor cell type. BMC Cancer. 2011;11:333.

49. Srivastava M, Pollard HB. Molecular dissection of nucleolin's role in growth and cell proliferation: new insights. FASEB J. 1999;13:1911-22.

50. Wu W, Munday DC, Howell G, Platt G, Barr JN, Hiscox JA. Characterization of the interaction between human respiratory syncytial virus and the cell cycle in continuous cell culture and primary human airway epithelial cells. J Virol. 2011;85:10300-9. 
51. Swedan S, Andrews J, Majumdar T, Musiyenko A, Barik S. Multiple functional domains and complexes of the two nonstructural proteins of human respiratory syncytial virus contribute to interferon suppression and cellular location. J Virol. 2011;85: 10090-100.

52. Lindquist ME, Lifland AW, Utley TJ, Santangelo PJ, Crowe JE Jr. Respiratory syncytial virus induces host RNA stress granules to facilitate viral replication. J Virol. 2010;84:12274-84.

53. Gutiérrez-Ortega A, Sánchez-Hernández C, Gómez-García B. Respiratory syncytial virus glycoproteins uptake occurs through clathrin-mediated endocytosis in a human epithelial cell line. Virol J. 2008;5:127.

54. Jeffree CE, Brown G, Aitken J, Su-Yin DY, Tan BH, Sugrue RJ. Ultrastructural analysis of the interaction between F-actin and respiratory syncytial virus during virus assembly. Virology. 2007; 369:309-23.

55. Chang TH, Segovia J, Sabbah A, Mgbemena V, Bose S. Cholesterol-rich lipid rafts are required for release of infectious human respiratory syncytial virus particles. Virology. 2012;422: 205-13.

56. Hegele RG, Sekhon MS, Kaan P. Towards systems biology of respiratory syncytial virus infections: seeing the need and preparing for prime time. Curr Respir Med Rev. 2008;4:29-34.

57. Ravi LI, Li L, Sutejo R, Chen H, Wong PS, Tan BH, Sugrue RJ. A systems-based approach to analyse the host response in murine lung macrophages challenged with respiratory syncytial virus. BMC Genomics. 2013;14:190.

58. - Wu W, Tran KC, Teng MN, et al. The interactome of the human respiratory syncytial virus NS1 protein highlights multiple effects on host cell biology. J Virol. 2012;86:7777-7789. This is a contemporary example of how systems biology and informatics approaches are yielding novel insights into RSV-host cell interactions.

59. Vardi L, Ruppin E, Sharan R. A linearized constraint-based approach for modeling signaling networks. J Comput Biol. 2012;19:232-40.

60. Wittig HJ, Cranford NJ, Glaser J. The relationship between bronchiolitis and childhood asthma. J Allergy. 1959;30:19-23.

61. Stein RT, Sherrill D, Morgan WJ, et al. Respiratory syncytial virus in early life and risk of wheeze and allergy by age 13 years. Lancet. 1999;35:541-5.

62. Sigurs N, Aljassim F, Kjellman B, et al. Asthma and allergy patterns over 18 years after severe RSV bronchiolitis in the first year of life. Thorax. 2010;65:1045-52.

63. Stein RT, Martinez FD. Respiratory syncytial virus and asthma: still no final answer. Thorax. 2010;65:1033-4.

64. Welliver RC, Wong DT, Sun M, Middleton E Jr, Vaughan RS, Ogra PL. The development of respiratory syncytial virus-specific IgE and the release of histamine in nasopharyngeal secretions after infection. N Engl J Med. 1981;305:841-6.

65. Frick OL, German DF, Mills J. Development of allergy in children. I. Association with virus infections. J Allergy Clin Immunol. 1979;63:228-41.

66. Lee KK, Hegele RG, Manfreda J, et al. Relationship of early childhood viral exposures to respiratory symptoms, onset of possible asthma and atopy in high risk children: the Canadian Asthma Primary Prevention Study. Pediatr Pulmonol. 2007;42:290-7.

67. Hegele RG, Robinson PJ, Gonzalez S, Hogg JC. Production of acute bronchiolitis in guinea-pigs by human respiratory syncytial virus. Eur Respir J. 1993;6:1324-31.

68. Buckner CK, Songsiridej V, Dick EC, Busse WW. In vivo and in vitro studies on the use of the guinea pig as a model for virusprovoked airway hyperreactivity. Am Rev Respir Dis. 1985;132: 305-10.

69. Ishida K, Kelly LJ, Thomson RJ, Beattie LL, Schellenberg RR. Repeated antigen challenge induces airway hyperresponsiveness with tissue eosinophilia in guinea pigs. J Appl Physiol. 1989;67: 1133-9.

70. Hegele RG, Hayashi S, Bramley AM, Hogg JC. Persistence of respiratory syncytial virus genome and protein after acute bronchiolitis in guinea pigs. Chest. 1994;105:1848-54.

71. Sutton TC, Tayyari F, Khan MA, Manson HE, Hegele RG. T helper 1 background protects against airway hyperresponsiveness and inflammation in guinea pigs with persistent respiratory syncytial virus infection. Pediatr Res. 2007;61(5 Pt 1):525-9.

72. Dakhama A, Bramley AM, Chan NG, McKay KO, Schellenberg RR, Hegele RG. Effect of respiratory syncytial virus on subsequent allergic sensitization to ovalbumin in guinea-pigs. Eur Respir J. 1999;13:976-82.

73. Tayyari F, Sutton TC, Manson HE, Hegele RG. CpG-oligodeoxynucleotides inhibit RSV-enhanced allergic sensitisation in guinea pigs. Eur Respir J. 2005;25:295-302.

74. - Zeng R, Li C, Li N, Wei L, Cui YX. The role of cytokines and chemokines in severe respiratory syncytial virus infection and subsequent asthma. Cytokine. 2011;53:1-7. This is a comprehensive review of inflammatory mediators and genetic determinants in severe forms of RSV infection and their sequelae.

75. - Ali S, Hirschfeld AF, Mayer ML, et al. Functional genetic variation in NFKBIA and susceptibility to childhood asthma, bronchiolitis, and bronchopulmonary dysplasia. J Immunol. 2013;190:3949-58. This describes the potential genetic "missing link" between RSV bronchiolitis and asthma.

76. Becker S, Koren HS, Henke DC. Interleukin- 8 expression in normal nasal epithelium and its modulation by infection with respiratory syncytial virus and cytokines tumor necrosis factor, interleukin-1, and interleukin-6. Am J Respir Cell Mol Biol. 1993;8:20-7.

77. Soukup J, Koren HS, Becker S. Ozone effect on respiratory syncytial virus infectivity and cytokine production by human alveolar macrophages. Environ Res. 1993;60:178-86.

78. Kaan PM, Hegele RG. Interaction between respiratory syncytial virus and particulate matter in guinea pig alveolar macrophages. Am J Respir Cell Mol Biol. 2003;28:697-704.

79. Hackett TL, Singhera GK, Shaheen F, et al. Intrinsic phenotypic differences of asthmatic epithelium and its inflammatory responses to respiratory syncytial virus and air pollution. Am J Respir Cell Mol Biol. 2011;45:1090-100.

80. Wong CM, Thach TQ, Chau PY, et al. Part 4. Interaction between air pollution and respiratory viruses: time-series study of daily mortality and hospital admissions in Hong Kong. Res Rep Health Eff Inst. 2010;154:283-362.

81. Vandini S, Corvaglia L, Alessandroni R, et al. Respiratory syncytial virus infection in infants and correlation with meteorological factors and air pollutants. Ital J Pediatr. 2013;39:1.

82. • Cruz-Sanchez TM, Haddrell AE, Hackett TL, et al. Formation of a stable mimic of ambient particulate matter containing viable infectious respiratory syncytial virus and its dry-deposition directly onto cell cultures. Anal Chem. 2013;85:898-906. This describes a new mechanism of prolonged RSV survival outside cells, with profound implications for virus viability and transmission.

83. Morris JA, Blount RE, Savage RE. Recovery of cytopathic agent from chimpanzees with coryza. Proc Soc Exp Biol Med. 1956; 92:544-50.

84. Chanock RM, Roizman B, Myers R. Recovery from infants with respiratory illness of a virus related to chimpanzee coryza agent. I. Isolation, properties and characterization. Am J Hygiene. 1957;66:281-90.

85. Chanock RM, Finberg L. Recovery from infants with respiratory illness of a virus related to chimpanzee coryza agent (CCA). II. Epidemiological aspects of infection in infants and young children. Am J Hygiene. 1957;66:291-300. 
86. Crowe JE Jr. Respiratory syncytial virus vaccine development. Vaccine. 2001;20(Suppl. 1):S32-7.

87. Kim HW, Canchola JG, Brandt CD, et al. Respiratory syncytial virus disease in infants despite prior administration of antigenic inactivated vaccine. Am J Epidemiol. 1969;89:422-34.

88. Waris ME, Tsou C, Erdman DD, Zaki SR, Anderson LJ. Respiratory synctial virus infection in BALB/c mice previously immunized with formalin-inactivated virus induces enhanced pulmonary inflammatory response with a predominant Th2-like cytokine pattern. J Virol. 1996;70:2852-60.

89. Boukhvalova MS, Prince GA, et al. The TLR4 agonist, monophosphoryl lipid A, attenuates the cytokine storm associated with respiratory syncytial virus vaccine-enhanced disease. Vaccine. 2006;24:5027-35.

90. - Tregoning JS, Wang BL, McDonald JU, et al. Neonatal antibody responses are attenuated by interferon- $\gamma$ produced by NK cells and T cells during RSV infection. Proc Nat Acad Sci USA. 2013;110:5576-81. This article casts doubt on design of vaccines to shift the host $T_{h} 1-T_{h} 2$ balance toward $T_{h} 1$ response.
91. Bystrom J, Al-Adhoubi N, Al-Bogami M, Jawad AS, Mageed RA. Th17 lymphocytes in respiratory syncytial virus infection. Viruses. 2013;5:777-91.

92. Quan F-S, Kim Y, Lee S, et al. Viruslike particle vaccine induces protection against respiratory syncytial virus infection in mice. J Infect Dis. 2011;204:987-95.

93. Mok $\mathrm{H}$, Cheng $\mathrm{X}, \mathrm{Xu} \mathrm{Q}$, et al. Evaluation of a measles vaccine virus as a vector to deliver respiratory syncytial virus fusion protein or Epstein-Barr virus glycoprotein gp350. Open Virol J. 2012;6:12-22.

94. McLellan JS, Correia BE, Chen M, et al. Design and characterization of epitope-scaffold immunogens that present the motavizumab epitope from respiratory syncytial virus. J Mol Biol. 2011;409:853-66.

95. Lindell DM, Morris SB, White MP, et al. A novel inactivated intranasal respiratory syncytial virus vaccine promotes viral clearance without $\mathrm{Th} 2$ associated vaccine-enhanced disease. PLoS ONE. 2011;6:321823. 